Published in Australian Planner (2008) 43 (3) 34-42

\title{
Barriers to implementing water efficiency practices in the built environment - the case of Melbourne and Bendigo, Australia
}

\author{
Dr Anna C. Hurlimann \\ Anna is a Lecturer in Urban Planning at the Faculty of Architecture Building and Planning, The \\ University of Melbourne
}

\section{Introduction}

Many urban and regional areas of Australia are facing a water crisis, with water storages reaching record low levels over the past decade. This crisis is due to many factors including increasing population, increasing urbanisation, and increasing variability in climate. Another contributing factor for Australia is a culture of excessive water use which was created during a period of relative water abundance (Davison, 2008). Australians are amongst the largest consumers of water in the world on a per capita basis (World Resources Institute et al., 2005). For residential properties, garden watering accounts for up to 50\% of consumption (Crockett and Carroll, 1997, Loh and Coghlan, 2003) in the absence of restrictions to water use. This situation is likely to become increasingly serious in the future. Rainfall variability is predicted to increase with climate change (Government of Victoria, 2006, Howe et al., 2005), resulting in 'drought' periods of longer duration, and rainfall periods of greater intensity. Two major challenges to the current built form of Australian cities will be the adaptive capacity ${ }^{1}$ of the existing built form, and the robustness of future built form. Blackmore and Plant (2008) advocate integrated urban water systems as a 'sustainable' approach to water management. They believe that adaptive capacity of such systems ultimately resides in institutions and individuals.

Australia's building stock has largely been built in denial of the drought-like climate which is its reality. Most homes and buildings do not incorporate water efficiency initiatives, or if so, the initiatives incorporated are limited and of a small scale. Our cities are constructed with centralised water and sewerage infrastructure - a paradigm which fosters a culture of excessive water use (Hurlimann, 2006). This form stifles the recreation of an ideal urban form that responds to drought and future challenges to cities. Allon and Sofoulis (2006) believe that the dominant discourse on water conservation in Australia has ignored how our large scale systems of supply shape expectations of use, and habits. They believe that discussion fails to recognise the obstacles to water saving presented by the water utilities, infrastructures and standard fillings themselves. Hawkins (2006) has a similar sentiment regarding sewerage infrastructure. Hawkins believes sewers have privatised waste, and left the public with the inability to imagine a different way of living with their waste.

There have been various initiatives instigated over the past decade which have attempted to respond to the increasing serious of the water crisis in Australia. These responses have been highly variable, ranging from mandating dual flush toilets, to the construction of new subdivisions which incorporate a 'third pipe' ${ }^{2}$, and to the introduction of high level water policy at the state and national level. Many of

\footnotetext{
${ }^{1}$ Defined by Norris et al. (2008) as resources with dynamic attributes i.e. resources that are robust, redundant, or rapidly accessible

${ }^{2}$ These 'third pipe' systems are also known as 'dual water supply systems'. They include two separate and distinct pipping systems, one which is used to transport water for potable (drinking) uses, the other for non-potable uses. This is in addition to sewage pipes.
} 
these policy initiatives aim to increase water efficiencies and promote new and alternative sources of water.

At the national level, the 2004 introduction of the National Water Initiative (Council of Australian Governments, 2004) has been influential. This intergovernmental agreement aimed to encourage water conservation in cities through better use of stormwater and recycled water. Various state level policies have been initiated as a result. For example, Western Australia's State Water Strategy set a target to recycle $20 \%$ of wastewater sources by 2012 (Government of Western Australia, 2003), and Victoria's now Department of Sustainability and Environment set a recycling target of 20\% of Melbourne's wastewater by 2010 (Government of Victoria, 2002). However, due to the increased urgency of the water crisis over the past five years these policies have in many instances quickly become redundant and superseded with more aggressive plans such as desalination.

While acknowledging much change is required to the culture and behaviour surrounding use of water in Australia, this paper focuses on urban planning policy and aims to identify the barriers which exist to a more sustainable approach to water management. These aims are addressed firstly through a discussion of the policy context for implementing sustainable built form in the state of Victoria. This is then followed by a discussion of the discretionary based planning system in Victoria. The author proposes that the discretionary policy approach has negative implications for achieving the objectives of sustainable water management. This proposition is then tested with built environment professionals in Melbourne and Bendigo in Victoria. The study's method is described, results presented and conclusions made.

\section{The policy context for implementing sustainable built form in the state of Victoria}

An overview of planning policy pertaining to environmental issues in Victoria is provided by Hurlimann (In Press) outlining the myriad of policies that exist. In addition to planning policy, the Victorian building regulations are also an important influence on built form. A five star standard for environmental design was introduced in July 2005. This standard requires all new homes in Victoria to include a range of energy efficiency and water saving features (Building Commission of Victoria, 2007). From May 2008, the five star standard was extended to cover renovations and relocation of homes. However, rating tools may not be the solution to delivering sustainable development alone, as found by Crawley et al. (2004) in the case of Brisbane City Council. Crawley et al. (2004) suggest that the development of a framework which is integrated across the whole corporate and land use planning process is more likely to deliver desired outcomes.

With regards to the issue of water efficiency, this paper argues that urban planning policy and building regulations have failed to adequately address the issue of water efficiency. It is acknowledged that policy initiatives have recently been introduced in an attempt to address sustainable water management. For example the 'Integrated Water Management' provision of the Victorian Planning Provisions (clause 56.07). However, it could be debated that the current policy is limited in its achievements (Hurlimann, In Press). Due to the lack of direct and strong policy and regulation relating to water conservation, companies in the built environment field have a critical role to play in motivating clients to incorporate water efficiency practices beyond these existing policies. A discussion surrounding development control, and the effectiveness of discretionary and mandatory policy is presented below.

\section{Discretionary nature of the Victorian planning system}

The Victorian planning system is a discretionary based planning system (Eccles and Bryant, 2006). The superiority of discretionary versus regulatory approaches is debated in global planning theory literature. This discussion has particular relevance for the implementation and success of policy 
pertaining to environmental sustainability including sustainable water management. Booth (1996) describes that in discretionary planning systems there is no absolute relationship between the plan and the development control decisions. Plans in such a system are indicative of policy but are not definitive. These systems are praised for their flexibility, however they may lead to policy that is implicit in the accumulation of individual decisions but is not evident in formal policy documents. A common criticism of these systems is that there is a notable absence of certainty (Booth, 1996, Tang et al., 2000, Tewdwr-Jones, 1999). Healey et al. (1988) believe there are obvious benefits in maintaining discretion in the decision making process to allow a high degree of adaptability to changing circumstances.

Booth (1996) describes regulatory systems as being ones in which planning control has to be clear in defining the rights of individuals as landowners and the precise limits to those rights. A strength of these systems is certainty - knowing in advance what is acceptable and the certainty of obtaining a favourable decision if all the regulations are met (Booth, 1996, Tang et al., 2000). Weaknesses of these systems include rigidity and inflexibility (Tang et al., 2000). Booth (1996) believes that regulatory systems may be easier to apply and that they decrease disagreement, but in practice they too often become the base-line for bargaining and negotiation, which fundamentally weakens their impact. Booth (1996) also highlights that many fixed rules do not accurately reflect the complexity of the urban environment and the goals of the planning system.

Such a discussion has also emerged in relation to environmental objectives. Wood and Becker (2005) identify tension between flexibility and uncertainty in decision making in the Environmental Impact Assessment (EIA) screening process in the UK. The authors found that discretionary judgement engenders flexibility within planning, and an ability to reflect environmental circumstances and social values when considering the significance of potential environmental effects. However, they also recognize that discretionary judgement can make accountability difficult and it has the potential to exacerbate uncertainty for developers and other stakeholders. Wood and Becker have identified that the resulting different approaches and interpretations of policy are leading to different courses of action, raising concerns with respect to the consistency of application of the EIA regulations across England and Wales. With regards to achieving sustainable development of brownfield (reclaimed) sites in the UK, Williams and Dair (2007a) advocate an objective led framework (discretionary approach) over prescribing the action needed to achieve those objectives (regulatory approach), because they allow for flexibility in interpretation. They argue that this flexibility is important because no two brown field sites are the same. However, in further research Williams and Dair (2007b) investigated barriers to meeting sustainability objectives in development in England. The barrier most frequently stated by stakeholders was that sustainability issues were never on the agenda. The researchers found that where particular measures were stipulated in statutory policy and regulations, they were addressed. Where there were no regulatory or policy responsibilities, objectives were often not considered. In many instances stakeholders lacked sufficient powers to enforce sustainable options because regulations and policies they are required to enforce are not stringent enough (Williams and Dair, 2007b). This suggests a regulatory approach is more likely to facilitate the achievement of sustainability objectives.

For the case of planning in Victoria, Eccles and Bryant (2006) note the debate about flexibility and certainty appears to be re-emerging. They acknowledge that a prescriptive approach would provide more certainty. Shaw (2003) believes that a strong policy based (discretionary) system has the capacity to regulate with the flexibility to support and inspire as well as refuse. 
This review of literature indicates, particularly for the case of sustainable built form, that a regulatory approach is preferable over a discretionary approach to development control, as it puts sustainability on the agenda of decision makers, requiring them to consider the sustainability objectives. However, it is acknowledged that some degree of flexibility to facilitate innovative approaches to environmental challenges would be optimal. Thus with regards to achieving the objectives of sustainable water management the literature indicates a regulatory approach would be preferable over a discretionary approach. This research aims to assess if this inference is true for Victorian policy, through the survey of built environment professionals ${ }^{3}$. The research agenda and study locations are now described.

\section{Research Agenda}

The challenges raised by the seriousness water crisis, the current (limited) water policy context in Australia, and the theoretical debates about optimal planning policy, gave rise to the following research questions to be explored through semi-structured interviews with built environment professionals in Victoria:

1) What barriers do built environment professionals face to implementing water efficiency practices in their projects?

2) How are water efficiency practices initiated?

3) What is the current role of urban planning policy with regards to influencing water efficiency uptakes?

4) Is there a difference in water efficiency practice between firms based in Bendigo and Melbourne?

\section{Study Locations}

The research was undertaken in two locations in the Australian state of Victoria. These locations were Melbourne, the state's capital city, and Bendigo a regional urban centre. It was thought important to explore the issue in both the state's capital city and a regional centre to see if issues encountered in the locations differed. The locations were also chosen for their different water contexts, particularly water availability. Melbourne has a population of 3.7 million people, and is predicted to grow to 4.7 million by 2030. Melbourne 2030 (Government of Victoria, 2002) is a key urban planning strategy guiding future growth of the city. Annual average rainfall (over the past 153 years) is $650 \mathrm{~mm} / \mathrm{year}$. The city's water is sourced from a series of dams. At the end of July 2008 the city's water storages were at $30 \%$ of capacity.

Bendigo is located $150 \mathrm{~km}$ north-west of Melbourne and has a population of approximately 97,000. Annual average rainfall (over the past 131 years) is $550 \mathrm{~mm} /$ year. Bendigo's water supplies reached a critically low level in June 2007 having only 4\% capacity of water storages (dams). Residents were on stage $4 \mathrm{a}$ (of 4 ) water restrictions. At that time Melbourne had $28.4 \%$ capacity of water storages (dams) full and was on stage 3 (of 4) water restrictions. Bendigo's residents were on emergency restrictions, with water for all but essential uses banned. In August 2007 a pipeline connecting Bendigo's water supply system with the Waranga Western Channel (part of the Goulburn-Murray Water system) was completed. In October 2007 'Stage 4 General Exemption' restrictions were introduced. This has seen a general exemption for all urban residential customers in the Coliban System, allowing them to water their gardens for up to two hours each week on specified days between 7pm and 8pm (for full details of water use restrictions see Coliban Water (2007)).

\section{Study Method}

The principal method employed in this research was a semi-structured interview. One representative from each of thirty companies were interviewed. The companies were randomly selected from the

\footnotetext{
${ }^{3}$ The term built environment professionals is used to describe those professions involved in the production and management of the built environment - cities and urban areas
} 
Bendigo and Melbourne business directories and were interviewed over the period December 2006 March 2007. The sample size was considered appropriate for this study which is qualitative in nature. It allowed the deep analysis of cases, which is a hallmark of qualitative inquiry (Sandelowski, 1995). The participants were from various built environment professions including architecture, building and development.

The semi-structured survey consisted of five major components: 1) general information about the respondent and company, 2) the respondents' knowledge of recycled water and water efficiency practices, 3) the extent to which water recycling and efficiency practices were incorporated in their projects, 4) the respondents' perception of recycled water and water efficiency knowledge gaps, barriers encountered to water initiatives, legislation and policy requirements, views on possible incentives and 5) personal attitudes. The Statistical Package for the Social Sciences (SPSS 2007) was used to collate and analyse the data.

\section{Results and Discussion}

The results of the study are reported under the following thematic headings, beginning with respondent characteristics. Tables presenting detailed information about the results can be found in the appendix to this article.

\section{Respondent characteristics}

Representatives from thirty companies were interviewed, fifteen each from Melbourne and Bendigo. Two females and twenty eight males were interviewed. The built environment areas represented included architectural firms $(n=10)$, building firms $(n=9)$, property development firms $(n=6)$ a consulting/planning/engineering firm, and the other two firms which were a combination of architectural/urban arts/urban design/planning.

\section{Type of clientele}

The respondents were asked what percentage of their developments were from particular building sectors. The dominant activity was identified as being greater than $50 \%$ of their activities. The companies interviewed had a range of clientele bases spread evenly between commercial, residential alterations and additions, residential - single dwellings, and residential - multi dwelling development. In total $7(23 \%)$ of those interviewed did not have a dominant activity i.e. there was not a single category that was greater than $50 \%$ of their activities (for further information see table one in the appendix).

\section{Location of clientele}

Respondents were asked about the location of their clientele base. Approximately one third of respondents predominantly operated in Bendigo, one third in Melbourne and one third had no dominant clientele base (for further information see table two in the appendix).

Respondents' position in their company

Respondents were asked what their position was in the company they represented. In total $50 \%$ of those interviewed were directors of the company, thus the predominant interviewees were representative of higher end / strategic aspects of the companies (for further information see table three in the appendix).

Company employees 
Respondents were asked how many employees their company had. The majority of respondents interviewed came from mid-sized companies with 4-45 employees (for further information see table four in the appendix), however representatives from a range of company sizes were interviewed.

\section{Knowledge and incorporation of water efficiency practices}

Respondents were asked to rate their knowledge of various water initiatives including water efficiency practices, grey water reuse, sewer mining, rain water tanks, water efficient fixtures, water efficient appliances, stormwater harvesting and water sensitive urban design (WSUD). This was self reported and rated on a scale of $0-10$ where $0=$ no knowledge and $10=$ excellent knowledge. The mean responses can be found in Table 5 in the appendix. The means for the Melbourne respondents were higher than the Bendigo respondents.

Paired sample t-tests were conducted to analyse if there were any differences in mean ratings between companies located in Bendigo and Melbourne. There was one significant difference (at the 0.05 level), WSUD for which Melbourne respondents rated their knowledge significantly higher than Bendigo respondents. There was a significant difference in mean variance between locations for sewer mining (standard deviation of mean for Melbourne was 3.5, while Bendigo was 2.1). This indicates there was a significantly greater variance in the ratings of Melbourne respondents. What must be acknowledged is that they are self reported knowledge ratings, and thus may not represent an actual difference in knowledge. A possible explanation for the significant difference in means for WSUD could be that respondents in Melbourne (as the state's capital) may have greater exposure to information than companies located in Bendigo.

\section{Recycled water}

Respondents were asked what percentage of their projects incorporate water recycling initiatives. Six respondents said none of their projects did, 12 respondents said between 5-35\% of projects did and 8 said $50-100 \%$ of projects (4 respondents did not give an answer). Respondents were asked to give details of these water recycling initiatives. Comments include (but are not limited to) the following:

\footnotetext{
"There is a lot of water recycling on rural sites with on site septic systems which use water on gardens, irrigation... These sites have to use a septic system but not necessarily waste water treatment plants."

"A lot on rural properties, treatment plants recycled water into garden beds. In town there are no septic tanks, not in sewered areas, however many clients ask for septic tanks, and ask if they can be used...."

"In rural areas there is greater capacity for storage [of water]."
}

These responses indicate that on rural properties which are unconnected to mains sewer systems and thus on septic systems, water recycling happens as a default for garden use. In sewered areas, policy barriers are faced to installing such systems. Other respondents provided details of water recycling initiatives which ranged from small scale industrial and residential examples, to large scale projects such as large office buildings and subdivisions. A number of respondents indicated they faced difficulties in implementing water recycling initiatives. Comments mainly related to disinterest on the part of the water authorities, and lack of market interest. Comments included (but are not limited to) the following:

\footnotetext{
"We approached the rural water authority to do grey water recycling on a particular project, but they were not interested."
} 
"Water recycling initiatives are not being thought about a present because projects are cost driven."

"Decisions are driven by fashion, and if it is marketable."

Respondents were asked who initiated the recycled water projects. Eight indicated the project was either driven by an individual from the company, or the company's philosophy, ten indicated the client was the driver, two policy, and one another unspecified source (nine did not respond). This indicates that, for the companies surveyed, planning policy does not provide impetus for water recycling initiatives.

Water efficiency initiatives

Respondents were asked what percentage of their projects incorporated water efficiency initiatives. Four respondents said between $30-50 \%$ of projects did, 8 said $55-95 \%$ of projects did, and 12 said $100 \%$ of projects did (6 respondents did not give an answer). Respondents were asked for details of these water efficiency initiatives. It became apparent that policy was the main driver for the incorporation of these initiatives. When asked who initiated these, 7 said current policy, 6 said the company philosophy, 4 said an individual within the company, 5 said the client, and 1 mentioned another source (7 respondents did not give an answer). Comments about water efficiency initiatives included the following:

\footnotetext{
"Water recycling is starting to catch up with energy rating system being implemented by the Building Code of Australia."
}

Things were difficult in the past, i.e. Council not exposed to rain water tanks.

However, it seems that things are shifting for one respondent who indicated:

"A few years ago it was driven by company incentive or client. Now it is more about policy guidelines by the BCA. The BCA energy requirement for a five star rating is either a rain water tank or solar hot water."

\section{Barriers identified to the incorporation of water efficiency practices}

Respondents were asked if they had encountered any barriers to incorporating water recycling or water efficiency practices into their projects. All indicated that they had faced barriers. Many acknowledged that the drought is increasing the uptake of these initiatives. The main barrier identified was related to cost (identified by 17 of the 30 respondents). Examples of comments include:

\footnotetext{
"The biggest barrier is cost - trying to get funding (long pay back period)...spending time on business cases as to why we should do it."

"Client acceptance is the biggest barrier (based on cost). If it costs nothing, they will accept it. Some clients are passionate, they will do it even if costs are high."

"It is harder in Bendigo to make it cost effective. The Water Authority and Council are not supportive in storm water harvesting. There are no incentives."

"Initial costs, people are not long term stayers."

"Initial set up cost, client does not wish to spend.... Budgets for construction are short term."

"Costs and payback period - it does not influence the builder. Jobs are won based on dollars rather than any green features. More innovation of architecture is required."

"When subdivision is smaller it is not cost effective."
} 
"Upfront costs, developers are reluctant to spend."

Other barriers identified related mainly, but not only to legislation and institutional impediments, and knowledge gaps. Examples include the following:

"The main barrier is apathy. Although attitudes have changed over the past three years...the drought has changed attitudes."

"The Environment Protection Agency (EPA) is a barrier with regards to septic tanks and not allowing them in all residential areas."

"The Country Fire Authority (CFA) will not connect unless it is Class A water....there is negativity using recycled water, generally from people who are not aware of it."

"There is no planning for recycling to houses. The water authority is a barrier."

"The main barrier is water supply authorities taking responsibility of grey water systems and technology, especially smaller decentralised systems, they prefer centralised systems.... Water authorities tend to be risk averse."

"The Environment Protection Authority (EPA) have set heavy requirements, the guidelines are onerous and complex particularly for single sites."

"Regulation is unclear and it does not make industry go forward."

"Education of the councils. There is a lack of understanding, particularly at local government."

"Knowledge - we are not pushing boundaries. Confidence of reusing water and the benefits of recycling need to be improved."

"The main barrier is knowledge of how well they perform (confidence) .......time will tell."

"The major obstacle has been the Health Department (lack of information). ... The Health Department can approve, but do not have any information on what you can do with grey water. Guidelines / approvals / basic specifications are required."

The responses above identify a number of institutions as providing barriers in some instances: Councils, the Environmental Protection Authority, water authorities, the Health Department and Country Fire Authority.

\section{Information needs identified}

Respondents were asked if they feel they need more information about water efficiency and water recycling practice. In total $22(73 \%)$ respondents indicated they need more information. The majority of respondents indicated that there is information out there, but it needs to be consolidated and clearer. Comments pertaining to this include those outlined below:

\footnotetext{
"We always need more information. We need a central clearing house. This would be useful and help with consistency."

"Industry needs support from government. Currently it is too convoluted and not clear."

"Lots of information is around, the challenge is to get it into a meaningful context."

"Information may come from many different sources.....it needs to be factual and consistent."
} 
"There are various legalities with recycled water and grey water, therefore more information is required."

"Information that supports a long term view is needed, but [we] can't find it."

"We require one common body of knowledge.....Advice should be independent and not connected to money. Policy is slowly becoming clearer."

The main bodies identified as already providing information were: the 'GreenPlumbers' association Sustainability Victoria, water authorities, the Royal Australian Institute of Architects, and the Australian Council of Built Environment Design Professionals' Environment Design Guide (but respondents indicated it needs updating). A number of respondents indicated they employ consultants to keep them up to date with information. Overall respondents indicated that an independent source would be ideal. Respondents identified that information should come from the following organisations: universities, the building commission, media, water authorities, and manufacturers. The ways respondents suggested this should be presented included information sessions and more general education, along with web based information. One respondent suggested that general community education would encourage more clients to innovate. The most commonly identified source of information at present was councils. However, many respondents said more guidance is needed from councils. This links with the discussion earlier in the paper indicating discretionary policy is unlikely to be successful in achieving sustainable water management aims. The built environment professionals interviewed were clearly calling for increased guidance from local government and policy. Many were also calling for local governments to lead by example:

\footnotetext{
"If council bring in regulations, they need to lead and show how it is done."

"If council make suggestions they should provide information regarding best practice in a particular area."

"Councils and water authorities have a fairly poor track record for engaging consultants regarding water recycling."
}

\section{Built environment professionals as motivators}

One third of respondents indicated that their company philosophy, or an individual from their company initiates the inclusion of water efficiency or water recycling initiatives into projects. Many indicated the frustration they faced when trying to encourage clients to include such initiatives, but that short term cost prevented the client from implementing them. One respondent indicated that clients come to them because of their 'green' expertise. It appears that for the companies interviewed, company or client initiative was the main driver of recycled water projects in a period of policy vacuum.

\section{Legislation}

Throughout the interviews, respondents made comments about current legislation, predominantly urban planning policy. One respondent said that Melbourne City Council's planning scheme provided impetus for the initiatives in one of their projects. Melbourne City Council has a specific local policy about sustainable office buildings - Clause 22.19 'Environmentally Sustainable Office Buildings.' There was clear acknowledgement by some respondents of the difference between guidelines and policy, and the implications of this. A difference between councils with regard to extent of and effectiveness of policy addressing water management was acknowledged. 
"They can now 'nail' you at the planning stage - Melbourne City Council have incorporated [these initiatives] in their planning scheme - legally part of their planning scheme, not just guidelines. Some other councils have a legal wish list but it does not have weight, it is not converted into legislation."

"Some councils are more progressive than others"

"Regulation needs to come from council strategy. Council and the water authority need to make it mandatory."

Respondents were specifically asked if they thought better planning policy or building policy and legislation could help. Twenty six respondents agreed that better policy and legislation would help implement the initiatives. They made a number of comments including the following:

"Legislation needs to be clearer."

"More consistency of planning policies between councils would help designers. Councils need to be consistent in their assessment. Can we centralise?"

People are becoming more aware due to drought... Some legislation is required from the council. There should be a state policy on water resources."

"It must be a statutory requirement."

“Mandating would assist.”

"Planning permits need to be overhauled, they are inconsistent and take time. The guidelines for planning are not straight forward...It needs to be discretionary, having experience, common sense and flexibility."

"The government must spend money and develop legislation to be supportive."

Four of the thirty respondents said they did not think policy could help. This was attributed to a mixed range of reasons, some respondents believed it would increase cost, others thought it is a practice, rather than policy matter. However, overall there was a call for a level playing field with legislation and initiatives to get incentives in place.

It was apparent that legislation was more influential with regards to water efficiency rather than water recycling. This was evident from respondents' comments regarding water efficiency initiatives:

"Basically we have to comply with the 5 star rating: solar hot water, water tanks, triple A rating for appliances are all required and we are well versed with these. A lot of these are minimum standards and we try to encourage more than this, bigger tanks etc."

"Legislation requires all houses to have a rain water tank or solar hot water. Some legislation does not apply to multi-residential. Developer driven projects are not usually 'green.' If the client is going to occupy the building there is more drive to implement green initiatives. Residential is far ahead of commercial (in the building code) for green initiatives, although commercial is now slowly moving."

"Dual flush toilets, shower heads etc are almost mandatory, but it depends on how it is managed."

"Local councils are pushing for urban design to consider water saving-doing so helps get it through council [approval process] quicker.”

"Policy and the current physical environment (drought) drive these initiatives."

“The National Built Environment Rating System (NABERS) helps these initiatives." 
"Legislation and regulation requiring we obtain 5 star rating [are why these initiatives are in place].

The developer would not do it if it was not required."

\section{Incentives}

Respondents were asked if they thought incentives should be offered to property owners, developers or others in the built environment industry to encourage the incorporation of water efficiency practices in development. Five respondents thought that incentives should not be offered with comments included the following:

\footnotetext{
"I do not favour rewards for doing the right thing. It should be mandated."

"Monetary incentives are not a good idea, they create a paper trail."

"If legislation is in place it should happen automatically (no permit otherwise). So the alternative in the current situation is to encourage."

"The planning legislation should be fast tracked...planning permits take 12 months to 2 years to obtain."
}

Twenty five respondents said that financial incentives should be provided to get the initiatives in place. This was a common theme throughout all aspects of the interviews. Comments that were made in other sections of the interviews include the following:

\footnotetext{
"Socially, people tend to stay in places short term now days, hence there is a short term vision and they do not want to outlay costs.

"It is different for first home buyers, they can't afford to be interested in these initiatives. There is a requirement to have solar hot water $(A \$ 4,000)$ or a rain water tank $(A \$ 2,000)$ to get a 5 star rating. It may not have a pay back period."

"The issue with water recycling is not a technological one, it is a cost issue. It depends on how passionate people are about it."

"Developers tend to look at the bottom line, councils should make it mandatory."
}

This indicates a dominant issue was the costs associated with these initiatives and the implications of these costs. It would be useful to conduct further research in the future regarding pricing options.

\section{Discussion and conclusions}

This paper focused on urban planning policy, aiming to identify the barriers which exist to achieving a more sustainable approach to water management. These aims were addressed through a discussion of the policy context for implementing sustainable built form in the state of Victoria and a discussion of the discretionary based planning system in Victoria. With regards to achieving the objectives of sustainable water management, the literature indicated that a regulatory approach would be preferable over a discretionary approach. This research then assessed if this inference is true for Victorian policy, through the survey of built environment professionals. This was seen as an important research need due to the predicted impacts on water resources due to climate change, increasing urbanisation, and increasing population.

The research provided a wealth of information about the water initiatives incorporated by the built environmental professionals interviewed, and the barriers they faced to implementing them. Many 
respondents acknowledged that the recent drought was a major influence on the incorporation of water efficiency (including water recycling) initiatives. The main barrier to implementing water efficiency initiatives (including water recycling) identified by the majority of respondents was financial costs. The majority of respondents indicated that the high upfront cost, and long payback period of these initiatives meant that most clients chose not to install them. Respondents indicated that developers were not interested in initiatives if they would increase financial costs. The majority of respondents indicated that they thought current policy was not adequately addressing water issues. They indicated that increased policy and regulation was required for water efficiency measures (including recycling) to allow a level playing field in the development industry (in relation to costs). The majority of respondents indicated policy should be mandatory in nature. This indicates, as consistent with literature discussed earlier in this paper, that a regulatory approach would be preferable over a discretionary approach to achieve the objectives of sustainable water management.

Of the water recycling initiatives currently in place, the main driver was found to be the respondents' company philosophy, or the client. For water efficiency initiatives currently in place, the main driver identified was policy. In relation to perception of knowledge of water recycling and water efficiency initiatives, Bendigo residents were found to rate their knowledge lower than Melbourne respondents.

It is acknowledged that the study has been qualitative in nature, and focused on a small number of companies (15 in each of the two locations - Melbourne and Bendigo in the state of Victoria). Further, more extensive research is recommended both in Victoria and other states to verify the results obtained in this study, and to further explore solutions. While acknowledging the limitations of this study, the following recommendations are made for the state of Victoria:

- More far-reaching and extensive water efficiency initiatives (than currently exist) should be mandated at various levels of policy - including planning policy. Some level of flexibility should be given to support innovation. It is important that these issues are addressed at the planning stage of development, as fundamental changes to aspects of design may be required.

- The principle above, is likely to apply to other aspects of sustainability (eg increased energy efficiency of buildings).

- The State Government of Victoria's Office of Water should set up an expert committee (composed of members from diverse disciplines) to review existing planning policy (eg the state planning policy framework and particular provisions) related to water initiatives. This review should be accompanied by the creation of solutions to dot point one above.

- Incorporation Melbourne City Council's Clause 22.19 'Environmentally Sustainable Office Buildings' into the planning schemes of other Councils should be considered.

- Proactive retrofits of existing buildings must be addressed in the future (potentially through retrofit requirements prior to sale of property). Our existing building stock is not sustainable at present.

- Bendigo respondents had a lower reported knowledge of water initiatives. It is recommended that government and industry bodies (such as the Planning Institute of Australia and the Australian Water Association) design and implement information sessions in regional areas.

- The information needs raised in this study should be addressed. A central point of information is recommended, perhaps as above through the Planning Institute of Australia, the Australian Water Association, or an independent body.

- These recommendations are likely to apply to other states of Australia.

If we are to build cities which will be resilient to future environmental challenges, including increasingly severe drought and climate change, we need to design policy that will achieve this aim rather than simply comfort ourselves that key words are addressed in policy, or that behaviour change 
will occur unaided. The representatives from the built environment disciplines interviewed for this research have indicated that stronger, regulatory policy should be facilitated. This would ensure a level playing field and thus facilitate sustainable water management, and would contribute to ensuring the security of future supply. A review of existing policy is required as a matter of urgency. The longer the delay, the less resilient our built environments will be.

\section{Acknowledgements}

This study was undertaken as part of a grant awarded to the author and Dr Dominique Hes from the Faculty of Architecture Building and Planning. The grant was funded by the University of Melbourne through their Early Career Research Grant Scheme. The author would like to thank all the participants in the study for their time and thoughtful comments, without which this study would not have been possible. Thanks to Mr Sebastian Immaraj for his diligent research assistance with this project. Thanks also to the two blind reviewers for their comments which helped strengthened the paper. Responsibility for any errors in the article remains with the author.

\section{References}

Allon, F. and Sofoulis, Z. (2006) Everyday Water: cultures in transition. Australian Geographer, 37, 45-55.

Blackmore, J. M. \& Plant, R. A. (2008) Risk and Resilience to Enhance Sustainability with Application to Urban Water Systems. Journal of Water Resources Planning and Management, 134, 224233.

Booth, P. (1996) Controlling Development: Certainty and discretion in Europe, the USA and Hong Kong, London, UCL Press.

Building Commission of Victoria (2007) 5 Star Standard for all new homes. Melbourne, Building Commission of Victoria. Available on line at:

http://www.buildingcommission.com.au/www/html/390-5-star-standard-for-all-new-homes.asp

Coliban Water (2007) Water Restrictions. Bendigo. Available on line at: http://www.coliban.com.au/savingwater/water restrictions.asp

Council of Australian Governments (2004) Intergovernmental Agreement on a National Water Initiative. Canberra, Australian Government. Available on line at: http://www.coag.gov.au/meetings/250604/iga national water initiative.pdf

Crawley, C., Beck, A., Berry, F. \& Swinson, V. (2004) Assessing Sustainable Urban Developments: Are rating tools the answer? Australian Planner, 41, 33-36.

Crockett, J. \& Carroll, L. (1997) Water: Consume Less and Pay More. Australian Water and Wastewater Association 17th Federal Convention. Melbourne, Australian Water and Wastewater Association.

Davison, G. (2008) Down the gurgler: Historical influences on domestic water consumption since 1850. 9th Australasian Urban History Planning History Conference Caloundra, University of the Sunshine Coast.

Eccles, D. \& Bryant, T. (2006) Statutory Planning in Victoria, Sydney, The Federation Press.

Government of Victoria (2002) New Water for Victoria, Victoria's Water Recycling Action Plan. Melbourne, Department of Natural Resources and Environment.

Government of Victoria (2002) Melbourne 2030: Planning for sustainable growth. Melbourne, Department of Infrastructure.

Government of Victoria (2006) Sustainable Water Strategy, Central Region Action to 2055, Melbourne, Department of Sustainability and Environment.

Government of Western Australia (2003) A State Water Strategy, for Western Australia. Perth, Government of Western Australia. 
Hawkins, G. (2006) Shit. The Ethics of Waste. Sydney, University of New South Wales Press. Healey, P., McNamara, P., Elson, M. \& Doal, A. (1988) Land Use Planning and the Mediation of Urban Change: The British Planning System in Practice, Cambridge, Cambridge University Press.

Howe, C., Jones, R. N., Maheepala, S. \& Rhodes, B. (2005) Implications of Potential Climate Change for Melbourne's Water Resources. Melbourne, Melbourne Water, CSIRO Urban Water and Climate Impact Groups.

Hurlimann, A. (2006) Water, Water, Everywhere - Which Drop Should be Drunk? Urban Policy and Research, 24, 303-305.

Hurlimann, A. (In Press) Environmental Planning in Melbourne - A critical analysis of the integrated water management provision. Urban Planning International.

Loh, M. \& Coghlan, P. (2003) Domestic Water Use Study In Perth, Western Australia 1998-2001, Perth, Water Corporation.

Norris, F. H., Stevens, S. P., Pfefferbaum, B., Wyche, K. F. \& Pfefferbaum, R. L. (2008) Community Resilience as a Metaphor, Theory, Set of Capacities and Strategy for Disaster Readiness. American Journal of Community Psychology, 41, 127-150.

Sandelowski, M. (1995) Sample Size in Qualitative Research. Research in Nursing and Health, 18, 179-183.

SPSS Inc. (2007) Statistical Package for the Social Sciences, Chicago, IL, SPSS.

Tang, B.-S., Choy, L. H. T. \& Wat, J. K. F. (2000) Certainty and Discretion in Planning Control: A Case Study of Office Development in Hong Kong. Urban Studies, 37, 2465-2483.

Tewdwr-Jones, M. (1999) Discretion, Flexibility, and Certainty in British Planning: Emerging Ideological Conflicts and Inherent Political Tensions. Journal of Planning Education and Research, 18, 244-256.

Williams, K. \& Dair, C. (2007a) A Framework for Assessing the Sustainability of Brownfield Developments. Journal of Environmental Planning and Management, 50, 23-40.

Williams, K. \& Dair, C. (2007b) What is Stopping Sustainable Building in England? Barriers Experienced by Stakeholders in Delivering Sustainable Development. Sustainable Development, 15, 135-147.

Wood, G. \& Becker, J. (2005) Discretionary Judgement in Local Planning Authority Decision Making: Screening Development Proposals for Environmental Impact Assessment. Journal of Environmental Planning and Management, 48, 349-371.

World Resources Institute, United Nations Environment Programme, United Nations Development Program \& The World Bank (2005) World Resources: 2005. Part II Data Tables, New York, Oxford University Press. 


\section{APPENDIX}

Table One: Dominant type of clientele

\begin{tabular}{|l|l|}
\hline Clientele category & Percentage of respondents (n) \\
\hline Commercial & $17 \%(5)$ \\
\hline Residential - alterations and additions & $17 \%(5)$ \\
\hline Residential - single dwelling & $17 \%(5)$ \\
\hline Residential - multi dwelling & $13 \%(4)$ \\
\hline Other & $13 \%(4)$ \\
\hline No dominant category & $23 \%(7)$ \\
\hline
\end{tabular}

Table Two: Dominant location of clientele

\begin{tabular}{|l|l|}
\hline Clientele category & Percentage of respondents (n) \\
\hline Bendigo & $37 \%(11)$ \\
\hline Other rural Victoria & $3 \%(1)$ \\
\hline Melbourne & $33 \%(10)$ \\
\hline Other Australia & $3 \%(1)$ \\
\hline International & $0 \%(0)$ \\
\hline No dominant clientele base & $24 \%(7)$ \\
\hline
\end{tabular}

Table Three: Respondents' position in the company

\begin{tabular}{|l|l|}
\hline Respondent position & Percentage of respondents (n) \\
\hline Employee & $26 \%(8)$ \\
\hline Director & $50 \%(15)$ \\
\hline Manager & $7 \%(2)$ \\
\hline General Manager & $7 \%(2)$ \\
\hline Owner & $3 \%(1)$ \\
\hline Other & $7 \%(2)$ \\
\hline
\end{tabular}

Table Four: Number of employees for respondents' companies

\begin{tabular}{|l|l|}
\hline Number of employees & Percentage of respondents (n) \\
\hline $1-2$ & $20 \%(6)$ \\
\hline $4-10$ & $33 \%(10)$ \\
\hline $11-45$ & $30 \%(9)$ \\
\hline $85-750$ & $17 \%(5)$ \\
\hline
\end{tabular}

Table Five: Mean responses for knowledge of various water efficiency practices

\begin{tabular}{|l|l|l|l|}
\hline Water efficiency practice & Total & Melbourne Average & Bendigo Average \\
\hline Water efficiency & 5.8 & 6.4 & 5.1 \\
\hline Water recycling implementation & 6.5 & 6.7 & 6.3 \\
\hline Grey water reuse & 6.6 & 7.1 & 6.0 \\
\hline Sewer mining & 2.5 & 3.1 & 1.9 \\
\hline Rain water tanks & 8.0 & 8.2 & 7.7 \\
\hline Eater efficient fixtures & 7.3 & 7.9 & 6.8 \\
\hline Water efficient appliances & 7.0 & 7.5 & 6.4 \\
\hline Stormwater harvesting & 7.0 & 7.5 & 6.4 \\
\hline Water sensitive urban design & 5.8 & 7.1 & 4.7 \\
\hline
\end{tabular}




\section{University Library}

\section{- M M N E R VA A gateway to Melbourne's research publications}

Minerva Access is the Institutional Repository of The University of Melbourne

Author/s:

Hurlimann, A

Title:

Barriers to implementing water efficiency practices in the built environment: The case of Melbourne and Bendigo, Australia

Date:

2008-01-01

Citation:

Hurlimann, A. (2008). Barriers to implementing water efficiency practices in the built environment: The case of Melbourne and Bendigo, Australia. AUSTRALIAN PLANNER, 45 (3), pp.34-42. https://doi.org/10.1080/07293682.2008.9982676.

Persistent Link:

http://hdl.handle.net/11343/59115 